\title{
A POLÊMICA SOBRE O BLOG “O MUNDO PRECISA DE POESIA”: UMA ANÁLISE SEMIÓTICA
}

\author{
Rafael Batista Andrade/Universidade Federal de Minas Gerais
}

RESUMO: Este artigo tem o objetivo de analisar duas notícias publicadas nos jornais $O$ globo e Folha de São Paulo, disponibilizadas online, sobre o projeto "O mundo precisa de poesia”, da intérprete brasileira Maria Bethânia. Os pressupostos teóricos assumidos para a realização das análises estão ancorados em algumas categorias do percurso gerativo de sentido da Teoria Semiótica francesa. Mais especificamente aquelas que estão enquadradas nos níveis narrativo e discursivo. Espera-se que este trabalho possa contribuir para um quadro de reflexões sobre o blog em geral e, em particular, sobre uma paródia do blog de Maria Bethânia, que nos remete à questão do bullying nesse espaço digital.

PALAVRAS CHAVE: Bullying. Temas. Figuras. Objeto de valor.

RÉSUMÉ: Cet article a comme objectif analyser deux publications dans les journaux $O$ globo et Folha de São Paulo, disponibles en ligne, sur le blog «O mundo precisa de poesia», de l'interprète brésilienne Maria Bethânia. Pour faire les analyses, nous utilisons quelques catégories de la théorie sémiotique fondée par A. J. Greimas, spécifiquement celles des niveaux narratif et discursif. Grâce à ce travail, nous souhaitons apporter des contribuitions pour les études sur le genre blog et, surtout, sur une parodie du blog de Maria Bethânia, qui fait preuve d'une affaire de harcèlement (bullying) dans le blog.

MOTS-CLÉS: Bullying. Thèmes. Figures. Objet de valeur.

\section{INTRODUÇÃO}

Algo imanente ao avanço tecnológico é a maneira com a qual os atores sociais se manifestam nas diferentes e novas formas tecnológicas desencadeadas por algumas ferramentas, como é o caso da internet. Mais particularmente o do blog: espécie de site ou página pessoal, contendo, geralmente, textos, imagens e links. Ele é atualizado periodicamente e seus usuários podem trocar experiências por comentários a posts, que, em geral, são organizados cronologicamente de forma inversa. É natural que esse uso promova também reflexões na academia sobre até que ponto essas inovações tecnológicas nos permitem estudar fenômenos linguageiros e discursivos.

Assim, o objetivo deste trabalho é analisar duas notícias sobre a proposta da artista Maria Bethânia de criar o blog "O mundo precisa de poesia”. A primeira notícia está disponibilizada na página do jornal $O$ globo e foi publicada no dia 17 de março de 2011. Já a segunda notícia está disponibilizada na página do jornal Folha de São Paulo e foi publicada no dia 
18 de março do mesmo ano.

Para a realização da análise, ancoramo-nos em algumas categorias do percurso gerativo de sentido proposto pela teoria Semiótica francesa. Primeiramente, faremos uma breve contextualização dessa teoria para, em seguida, analisarmos o corpus em questão. Enfim, após essa abordagem, apresentaremos as considerações finais deste artigo.

\section{O PERCURSO GERATIVO DE SENTIDO: UMA PROPOSTA SEMIÓTICA}

Denomina-se percurso gerativo de sentido uma importante parte do quadro teóricometodológico da Semiótica francesa, também designada Semiótica Greimasiana em função de seu fundador, Algirdas Julien Greimas. Esse percurso gerativo de sentido abarca o plano de conteúdo, embora o postulado da teoria também proponha estudos voltados para o plano de expressão.

O percurso gerativo de sentido é dividido em três níveis que se articulam e se complementam. Todos esses níveis são dotados de uma sintaxe e de uma semântica. De acordo com Fiorin (2008, p. 20), "na Semiótica, a sintaxe contrapõe-se à semântica. Aquela é o conjunto de mecanismos que ordena os conteúdos; esta, os conteúdos investidos nos arranjos sintáticos”.

O nível fundamental é aquele em que se encontram as oposições de base do texto, segundo as valorizações eufóricas (positivo) ou disfóricas (negativo), o que geralmente pode ser representado pelo quadrado semiótico. Este é o nível mais profundo do texto. Ou seja, é o nível com o maior número de elementos invariáveis.

No nível narrativo, procura-se descrever as relações dos sujeitos com os objetos e com outros sujeitos. Diz-se que esse é o nível actancial e o nível das modalizações. Trata-se de uma interposição entre o nível anterior e o próximo. É a partir de um aprofundamento desse nível que a teoria chegará a uma proposta de estudos das paixões, denominada, hoje em dia, Semiótica das Paixões. Levam-se em conta os estados de alma dos sujeitos, entendendo as paixões como "efeitos de sentido de qualificações modais que modificam o sujeito” (MATTE; LARA, 2009, p. 58). Ressaltamos a importância que o termo modalidade passou a ter nos estudos semióticos. De modo mais simplificado, podemos dizer que as modalidades são as condições necessárias ou facultativas da ação transformadora dos actantes. Sem entrarmos muito nos detalhes da tipologia das modalidades e na relação entre elas e a questão da tensividade, proposta teórica mais recente da Semiótica, recorremos a este excerto que explica o valor do termo modalidade usado neste trabalho: "a modalidade modifica a relação entre o sujeito e o objeto, ou então, ela modifica a relação entre o sujeito e um terceiro actante. O querer e o saber modificam a relação entre o sujeito e seu objeto" (FONTANILLE, 2011, p. 175).

Por fim, o nível discursivo é o nível mais concreto do discurso, em que são estudados os temas, as figuras, as aspectualizações de tempo e de espaço, além das debreagens. Nesse último nível, fica bastante visível a evolução da teoria, sobretudo por revelar-se agora sob uma influência da Teoria da Enunciação de Benveniste.

Para a realização de nossa análise, é imprescindível a exposição desses conceitos. Para Barros (2008, p. 69), tematizar um discurso consiste em "formular os valores de modo abstrato e organizá-los em percursos”. Para examiná-los “devem-se empregar princípios da análise semântica e determinar os traços ou semas que se repetem no discurso e o tornam coerente”. Ainda segundo a 
autora, "pelo procedimento de figurativização, figuras do conteúdo recobrem os percursos temáticos abstratos e atribuem-lhes traços de revestimento sensorial” (BARROS, 2008, p. 72).

\section{ANÁLISE DO CORPUS}

A primeira questão que levantamos é que a notícia procura simplesmente relatar um acontecimento. Nos casos a serem analisados, o que se noticia é a possibilidade do patrocínio do blog da intérprete Maria Bethânia. Precisamos, então, descrever, a partir de elementos do nível narrativo do percurso gerativo de sentido, alguns dados que estão pressupostos na notícia, pois, como sabemos, por meio dos programas narrativos chegaremos a operações de natureza lógica que resumem as relações entre sujeitos e sujeitos e objetos. A partir daí, partimos para a análise do nível discursivo, em que se manifestam temas e figuras em que subjazem valores para persuadir o enunciatário.

Para isso, dividimos a análise em três etapas, com a finalidade de evidenciar como as duas notícias se contrapõem e deixam pistas que revelam, pelas tramas do discurso, aspectos relevantes que dizem respeito ao Cyberbullying e à própria importância da descrição do discurso para seu estudo no campo da Linguística relacionada às novas tecnologias.

\subsection{Um percurso gerativo de uma mega-produção virtual}

Para iniciarmos a análise da primeira notícia, passemos à leitura desta, que optamos por citar abaixo na íntegra.

Blog de Maria Bethânia sofreu ajuste orçamentário de R\$ 440 mil

O projeto original do blog "O mundo precisa de poesia", de Maria Bethânia, pedia permissão para captar a quantia de R 1.798 .600 em patrocínio. Embora a proposta tenha sido autorizada pela Comissão Nacional de Incentivo à Cultura, o valor foi reajustado para $\mathrm{R} \$ 1.356 .858$, cerca de R\$ 440 mil a menos.

A informação, disponível em relatório divulgado nesta quarta-feira (16) no site do Ministério da Cultura ${ }^{\mathrm{i}}$, foi confirmada pelas assessorias de imprensa do MinC e da cantora.

O aval do ministério permite que Bethânia busque patrocínio através da Lei Rouanet, que garante abatimento de impostos em troca do incentivo cultural. Ela tem o prazo de 1 ano para fazer isso, período que pode ser renovado por mais seis meses.

Segundo a porta-voz de Bethânia, a quantia original cobriria os custos de uma produção completa: "gastos com a equipe, filmagem, direção, coordenação, correio, xerox... É normal haver esse ajuste do MinC em qualquer projeto. Nos adaptaremos a ele.”

Segundo a página do ministério, onde o projeto está descrito, a proposta prevê a criação de um blog com posts diários em vídeo. A direção dos filmetes ficará a cargo do cineasta Andrucha Waddington, responsável pelo documentário "Maria Bethânia - pedrinha de Aruanda" (2007).

Cada clipe terá cerca de dois minutos e poderá ser em cor ou em preto e branco. Na ficha com os dados básicos do projeto, disponível para consulta, há outra descrição da proposta: 
"A ideia é invadir a internet com lirismo, delicadeza e difundir a cultura na rede. Será um calendário virtual, que apresentará ao público 365 pílulas diárias de pura poesia."

A previsão é de que a página seja realizada entre junho de 2011 e junho de 2012.

O site é inspirado no espetáculo "Bethânia e as palavras", em que a artista recita poemas e trechos de textos de escritores como Fernando Pessoa, Guimarães Rosa, Manuel Bandeira e Sophia de Mello. A página será coordenada pelo antropólogo Hermano Vianna.

\section{Polêmica}

Na manhã desta quarta-feira (16), o jornal "Folha de S. Paulo" publicou a notícia de que a artista conseguiu autorização do MinC para construir seu blog.

A notícia repercutiu com força dentro do Twitter. Durante o dia inteiro o nome da cantora esteve entre os tópicos principais do microblog. A grande maioria das mensagens era contra a aprovação do Ministério da Cultura.

Em comunicado divulgado no final da tarde de quarta-feira, o $\underline{\text { MinC afirmou que aprovou o }}$ projeto de Bethânia apoiado em "critérios técnicos e jurídicos"iii e que "rejeitar um proponente pelo fato de ser famoso, ou não, configuraria óbvia e insustentável discriminação".

O Ministério da Cultura é chefiado por Ana de Hollanda, irmã do compositor Chico Buarque de Hollanda.

Nessa notícia, o sujeito Maria Bethânia, doravante SM, para realizar a performance de criar o blog "O mundo precisa de poesia”, quer entrar em conjunção com aproximadamente R $\$ 1,8$ milhão. Esse dinheiro é o objeto de valor modal para que SM atinja o seu objeto de valor descritivo: o blog.

SM foi sancionada positivamente pela Comissão Nacional de Incentivo à cultura com o valor de R\$1.798,600, disponibilizado durante um ano. Essa sanção positiva deve-se ao reconhecimento da modalidade de SM: sabe fazer um blog. Entretanto, a análise do nível discursivo do percurso gerativo de sentido nos permite evidenciar esse objeto de valor de forma mais concreta. Como afirma Fiorin, "um objeto narrativo, por ser mais abstrato, pode ser concretizado de múltiplas maneiras. Assim, o objeto de valor /riqueza/ pode ser concretizado como pote de ouro no fim do arco-íres, jóias, ações, obras de arte etc.” (FIORIN, 2009, p. 37).

No caso dessa notícia, a análise sêmica de "lirismo”, “delicadeza”, “difundir a cultura na rede" e "calendário virtual” revela-nos temas como responsabilidade social e cultural e o papel de humanização da literatura presentes no projeto da intérprete. Por tabela, o objeto de valor blog é concretizado como uma obra de arte disponibilizada via internet. Nesse caso, é bom ressaltar que aquela sanção positiva deve-se ao reconhecimento do saber fazer artístico de SM. Ora, não se trata somente de um saber fazer um blog, mas sim de um saber fazer Arte de forma inovadora e ao mesmo tempo com alcance popular.

O nível discursivo nos revela também a dimensão do projeto por meio do percurso figurativo. As figuras "Equipe de filmagem”, “direção”, “coordenação” "Andrucha Waddington”, “espetáculo 'Bethânia e as palavras””, "Fernando Pessoa”, “Guimarães Rosa”, "Manuel Bandeira”, “Sophia de Mello” e "antropólogo Hermano Vianna” revelam a dimensão de um trabalho artístico que envolve profissionais capacitados para o desenvolvimento de um blog artístico e não simplesmente de um blog qualquer. Ou seja, o blog “O mundo precisa de poesia” pode ser comparado a produções cinematográficas, teatrais e musicais, ou ainda, à reunião de tudo isso. Portanto, esse projeto seria uma espécie de uma megaprodução virtual. Essa conclusão leva em 
conta a análise temático-figurativa, o que justifica o custo da obra e a sanção positiva do Minc.

Todos esses dados estão implícitos nessa notícia e, através da análise pelas categorias fornecidas pela teoria Semiótica francesa, podemos ver um determinado "parecer do sentido" sobre tal texto. O sentido de que, embora o objeto de valor modal seja visto como absurdo por alguns leitores, e, principalmente, por muitos blogueiros (na parte polêmica temos que "a grande maioria das mensagens era contra a aprovação do Ministério da Cultura”), a notícia procura persuadir o enunciatário por meio, principalmente, dos percursos temático-figurativos, de que a sanção positiva leva em consideração o blog como objeto de valor artístico.

É claro que, como há uma tentativa de imparcialidade nesse gênero discursivo, esse parecer de sentido pode concorrer com outro(s) sentido(s). Um exemplo disso é o fato de o texto terminar expondo que o "Ministério da Cultura é chefiado por Ana de Hollanda, irmã do compositor Chico Buarque de Hollanda”. A inclusão dessa figura parece persuadir o enunciatário a ir contra a sanção positiva do Minc por deixar a impressão de um possível nepotismo no julgamento da proposta.

Apesar dessa tentativa de imparcialidade, vimos que o enunciador joga mais com valores positivos para persuadir o enunciatário a ver o objeto de valor artístico de forma positiva e que, por isso mesmo, uma megaprodução virtual exigiria um alto investimento financeiro. Será que esses valores também serão encontrados na análise da segunda notícia?

\subsection{Um percurso gerativo de uma "arte instantânea”}

Vejamos agora a segunda notícia que constitui o corpus do presente trabalho, começando por sua leitura.

\section{Inspirado em Bethânia, jornalista lança blog de poemas "a um real"}

volvendo o blog de poesia de Maria Bethânia, que recebeu autorização do Ministério da Cultura para captar R\$ 1,3 milhão por meio da Lei Rouanet, continua repercutindo na internet.

Além de se manter entre os dez assuntos mais comentados do Twitter desde quarta-feira, o tema tem inspirado uma série de iniciativas e paródias na rede. No dia em que a decisão do MinC foi noticiada, o jornalista Fred Leal, 28, criou o blog 365 Poemas a um Realiii . A página, que ele afirma ter criado em menos de uma hora, se apropria da proposta de Bethânia e disponibiliza, a cada dia, um vídeo com um poema sendo declamado.

"Só quero mostrar que a Lei Rouanet é abusada por quem possui o poder e o conhecimento. Não funciona como instrumento de inovação, por melhor que seja sua intenção", diz Leal. "A Bethânia está pedindo R\$ 1,3 milhão por algo que eu fiz em 15 minutos".

Ele conta que, duas horas depois de colocar o blog no ar, já tinha mais de dez "ofertas" de vídeos, e que o estoque atual já permite abastecer a página por pelo menos 20 dias. O material é avaliado previamente. "Não é só mandar e postar. Se a Bethânia pode ter critérios, eu também tenho."

Os vídeos são apresentados com o nome do declamante e a legenda "Orçamento: R\$1,00". No mais recente, publicado hoje, o cantor Thiago Pethit recita, em 20 segundos, o texto "Vinis Mofados", de Ramon Mello.

No caso desse segundo texto, é noticiada a criação do blog “365 poemas a um real”. Este se constitui um objeto de valor modal, pois o seu objetivo é a crítica à aprovação do blog "O mundo precisa de poesia”. A notícia evidencia a facilidade com a qual o jornalista Fred Leal diz ter entrado em conjunção com o blog “365 poemas a um real”. Ao demonstrar isso, o jornalista sanciona negativamente o Minc por aprovar o projeto da artista: "a Bethânia está pedindo R\$ 1,3 
milhão por algo que eu fiz em 15 minutos".

No entanto, uma análise temático-figurativa desta última notícia evidencia apenas os temas da rapidez e da facilidade de se criar um blog. Embora o jornalista diga que possui critérios, em momento algum, analisando as tramas do discurso, conseguimos mostrar que seu blog possui critérios artísticos.

Passemos, então, à comparação da análise dessas duas notícias, por meio de dados já apresentados e também de categorias de mais um patamar de análise da Semiótica francesa: a Semiótica das Paixões.

\subsection{Objetos de valores, o saber fazer arte e as paixões}

Ao compararmos os percursos temático-figurativos das duas notícias, percebemos, nitidamente, a diferença entre um objeto de valor artístico e de um objeto de valor não artístico. E, como vimos, a sanção do Minc tem justamente a ver com o saber fazer Arte do sujeito Maria Bethânia. Esse importante órgão público da cultura leva em consideração o blog dessa intérprete como arte: em comunicado divulgado no final da tarde de quarta-feira, "o Minc afirmou que aprovou o projeto de Bethânia apoiado em critérios técnicos e jurídicos”.

É preciso levar em conta, ainda, o fato explicitado nos dois textos de que as notícias referentes ao projeto da intérprete estavam gerando grande repercussão midiática. Assim, a paródia apresentada na segunda notícia aparece como um exemplo de várias sanções negativas à aprovação do blog "O mundo precisa de poesia”. Por isso, mostraremos agora uma análise baseada na Semiótica das Paixões, visto que a paródia está sendo levada em conta como um caso de bullying.

Até o presente momento, a análise efetuada baseou-se em grande parte nos "estados de coisas”. Porém, os estudos semióticos também têm se enveredado a estudar os "estados de alma”, ou seja, as vivências passionais do sujeito de estado.

No caso em questão, o jornalista Fred Leal é um antissujeito de Maria Bethânia e, com a paródia "365 poemas a um real”, ele desqualifica o saber fazer da Intérprete. Com isso, percebemos o desencadeamento da paixão "silenciamento". SM não se manifestou a respeito do assunto em nenhuma mídia.

Estamos considerando esse caso como bullying pelo fato de considerarmos essa paródia como um dos muitos atos violentos, em termos psicológicos, praticados por muitos blogueiros ao terem conhecimento da noticia sobre o projeto "O mundo precisa de poesia". O que certamente causou dor e angustia em SM, pois, ao julgarem o pedido de verba para seu projeto como abusivo, colocaram em dúvida sua integridade artística por não darem crédito ao seu saber fazer Artístico. Além disso, o outro aspecto fundamental para podermos caracterizar este caso como bullying é a relação desigual de poder. Essa relação é interessante nesse caso porque aparece invertida: houve um julgamento de que por ser famosa, a intérprete estaria abusando do dinheiro público.

\section{CONCLUSÃO}

A análise nos revela que as notícias investigadas neste artigo evidenciam o objeto de 
valor blog de forma muito diferente. Essa diferença torna-se perceptível, principalmente, pela análise temático-figurativa que distingue o blog como objeto de valor artístico e não artístico, o que é primordial para entender o posicionamento dos blogueiros contra a sanção positiva do Minc em relação ao blog “O mundo precisa de poesia”.

Portanto, o blog pode ser visto, às vezes, como um certo repositório de sentimentos em que blogueiros procuraram difamar a imagem de uma artista, mas sem levarem em conta a diferença entre objeto artístico e objeto não artístico. Ao tomarmos a paródia apresentada como um exemplo de textos que se opunham à aprovação do projeto de Maria Bethânia, lançamos a hipótese de que os antissujeitos da intérprete parecem agir, nesse, relativamente, novo espaço de interação tecnológica, apenas sob o ponto de vista do "estado de alma” e ignoram os "estados de coisas".

Esse fato nos leva a uma das questões mais importantes do ensino de língua materna (e também de línguas estrangeiras), que é a questão da formação do leitor crítico e também do produtor de texto crítico, seja em suportes tradicionais ou nos mais recentes. Podemos chamar de comentários críticos certos textos que circulam em nossa sociedade, como boa parte dos textos publicados em blogs?

Certamente, essa é uma questão que merece uma atenção ainda maior de pesquisadores inseridos na área das Ciências da Linguagem. Seria interessante a elaboração de trabalhos que se dedicassem a investigar a maneira de construção dos discursos em textos publicados em blog para se verificar a ocorrência de manifestação de elementos dos "estados de coisas" como fator de criticidade presente nesses textos. Para isso, mecanismos de interpretação do discurso, como os expostos na análise, são fundamentais. A diferença entre objeto de valor artístico e não artístico, por exemplo, até pode parecer um pouco óbvia, mas sua percepção nas tramas do discurso, como vimos, não.

Além disso, vale a pena lembrar que o baixo grau de criticidade sobre o assunto foi tanto que não houve nem um comentário pertinente sobre a importância dos poemas (recitados) por Maria Bethânia ao longo de sua trajetória artística. Aliás, o fato dessa intérprete recitar poemas (e também textos de outros gêneros) antes de interpretar uma canção constitui-se um campo de pesquisa relevante para os estudos da linguagem. Isso porque esse fenômeno discursivo coloca em evidência a hibridização de textos com importantes diferenças no plano de expressão e, decerto, com implicações desses fatores em relação aos efeitos de sentido pretendidos com a junção de poemas e canções. Este é mais um diferencial do objeto de valor artístico na carreira dessa intérprete.

\section{REFERÊNCIAS}

BARROS, Diana Luz Pessoa de. Teoria semiótica do texto. São Paulo: Ática, 2008.

BLOG de Maria Bethânia sofreu ajuste orçamentário de R\$440,00 mil. O globo. São Paulo, 17 mar. 2011. Disponível em <http://g1.globo.com/pop-arte/noticia/2011/03/blog-de-maria-bethaniasofreu-ajuste-orcamentario-de-r-440-mil.html>. Acesso em 23 out. 2011.

FIORIN, José Luiz. Em busca do sentido: estudos discursivos. São Paulo: Contexto, 2008. 
FIORIN, José Luiz. Elementos de análise do discurso. São Paulo: Contexto, 2009.

FONTANILLE, Jacques. As modalidades. In: FONTANILLE, Jacques. Semiótica do discurso. Tradução de Jean Cristtus Portela. São Paulo: Contexto, 2011. p. 169-185.

INSPIRADO em Bethânia, jornalista lança blog de poemas “a um real”. Folha de São Paulo. 18 mar. 2011. Disponível em <http://www1.folha.uol.com.br/ilustrada/890805-inspirado-em-bethaniajornalista-lanca-blog-de-poemas-a-um-real.shtml >. Acesso em 23 out. 2011.

MATTE, Ana C. F; LARA, Gláucia M.P; Ensaios de semiótica: aprendendo com o texto. Rio de Janeiro: Nova Fronteira, 2009. 
i Link citado: $<$ http://www.cultura.gov.br/site/wp-content/uploads/2011/02/CNIC-184.pdf $>$.

ii Link citado: $<$ http://g1.globo.com/pop-arte/noticia/2011/03/blog-de-bethania-foi-aprovado-por-criterios $>$.

iii Link citado: $<$ http://fubap.org/365poemas/>. 